\title{
Development of herpetic infection associated with stroke and its correction with acyclovir
}

\author{
Alla Gumenyuk ${ }^{1}$, Natalia Motorna ${ }^{1}$, Svetlana Rybalko ${ }^{2}$, Sergey Savosko ${ }^{1}$, \\ Liudmyla Sokurenko ${ }^{1}$, Daria Starosyla ${ }^{2}$, Yuri Porva ${ }^{2}$, Yuri Chaikovsky ${ }^{1 *}$ \\ ${ }^{1}$ Bogomolets National Medical University, T. Shevchenko boulevard 13, 01601, Kyiv, Ukraine \\ ${ }^{2}$ Gromashevsky L.V. Institute of Epidemiology and Infection Diseases, NAMS of Ukraine, Amosova 5, 03038, Kyiv, Ukraine
}

\section{ARTICLE INFO}

Received 25 October 2016

Accepted 23 January 2017

\section{Keywords:}

HSV I,

Herpes Simplex Virus,

stroke,

acyclovir,

Vero cell culture.

\begin{abstract}
Background: Herpes simplex virus (HSV) is prevalent in today's world population, and there is evidence of potential HSV reactivation in patients with immune deficiency induced by acute stroke. However, the data on the use of antivirals in the setting of stroke are scarce. The aim of this study was to evaluate the reactivation of HSV-1 in patients with stroke, using several methods, and to assess the efficacy of acyclovir in the treatment of experimental stroke. In the employed methodology, PCR and dot-ELISA were used to detect the occurrence of HSV-1 in patients with acute stroke. White mice were infected with HSV-1 and experimental stroke was simulated. The infected mice with stroke were subdivided into two groups: one of them received no treatment, while the other one was treated with acyclovir. The level of HSV-1 reactivation was determined by the methods used in human patients. The brain tissue of experimental animals was also subjected to morphological and morphometrical study. The results of such work reveal that, by the applied serological method, HSV-1 was found in all patients with stroke. Herein, the increased level of HSV-1 was seen in the brain tissue and blood in $100 \%$ of the experimental infected animals. However, the use of acyclovir suppressed reproduction of HSV-1. Hence, it can be concluded that clinical and laboratory studies have demonstrated the different sensitivity of Dot-Elisa and PCR, with the former being more sensitive. Moreover, the use of acyclovir in the experiment inhibited viral reproduction and further development of viral infection. Still, chemic lesions in the brain persisted.
\end{abstract}

\section{INTRODUCTION}

Cerebrovascular accidents are one of the leading contributors to morbidity and mortality [11]. The algorithm of first aid, treatment and rehabilitation of patients with stroke based on clinical observations and experimental studies is well described [1,7], yet, the infectious process, which can develop in the presence of immune deficiency in patients with acute stroke, has not received due attention. It has been demonstrated that Herpes simplex virus (HSV type I and II), prevalent in the general population, may cause meningitis and vasculitis in patients with stroke [9]. That is why reactivation of HSV in neurons, the budding of virions from the infected cells and subsequent cell death are a separate issue of disease pathogenesis. Moreover, the virus can be detected

\footnotetext{
* Corresponding author

e-mail: yuchaiko@i.ua

phone: +38 (044) 454-49-89
}

only when reactivated, which is the result of the immune system being compromised [6].

In our previous study [4], we have shown that the experimental ischemic brain damage was a factor of the HSV-1 reactivation being characterized by a higher rate of neurodegenerative changes in the hippocampus, as compared to the neuroinfection or the impairment of cerebral circulation not related to infection. The aim of this study was to evaluate the reactivation of HSV-1 in patients with stroke, using several methods, and to assess the efficacy of an antiviral drug acyclovir in the treatment of experimental stroke.

\section{MATERIALS AND METHODS}

In this study, we attempted to simulate one of the most common clinical cases of complications in patients with impaired brain circulation, including hemorrhagic stroke. We tried to simulate in laboratory animals, the pathological 
process that by the specific features of the development and sequence of events (episodes of damage) were most similar to clinical conditions. This we felt was important for further pre-clinical study of the efficacy of antiviral drugs in animals with comorbidities, not just the primary viral infection. For the latter, experimental models are actively applied and accepted. Accordingly, the methodology of our research included the following steps:

1. Laboratory determination of the presence of HSV-1 in patients with stroke.

2. Simulating of local hemorrhagic stroke in animals with latent infection.

3. Evaluating the efficacy of antiviral drug acyclovir in the treatment of acute infection with HSV-1 after simulation of hemorrhagic stroke in animals.

To establish persistent herpes infection in patients with acute stroke, we first conducted laboratory determination of HSV-1 in the blood of 7 patients with acute stroke (3-7 days after the stroke episode, the acute period). PCR and dot-ELISA were then used to detect HSV-1 in the patients' sera, and to determine the infectious titer in Vero cell culture. HSV level in patients was determined in the clinical laboratory in the course of the standard complete blood cytology and biochemistry testing. The patients gave their written informed consent to using these data for analytical and statistical evaluation.

Our experiment was conducted on white mice weighing 18-20 g. The animals were subdivided into 3 groups (Tab. 1).

Table 1. The groups of animals

\begin{tabular}{|c|l|c|}
\hline \multicolumn{2}{|c|}{ Group } & N of animals \\
\hline 1 & Control, intact mice & 10 \\
\hline 2 & HSV-1 with hemorrhagic stroke & 37 \\
\hline 3 & HSV-1 with hemorrhagic stroke+acyclovir & 48 \\
\hline
\end{tabular}

In our experiment, we simulated experimental stroke and subsequent reactivation of HSV-1 according to the development and sequence of events (episodes of damage similar to clinical conditions). Doing such was important for further preclinical study of the efficacy of the tested antiviral drug in animals.

To infect the laboratory animals, we used the freeze-dried HSV type I VC strain. $0.03 \mathrm{ml}$ of viral material, which equals to LD50. This was inoculated into the brains of the mice. Initial symptoms of the infectious condition in the control were observed in 5-6 days after the infection, and reached their maximum by day 13-14, with the following subsidence of symptoms and recovery of animals. We assume that this is the time when HSV-I transfers into its latent form. This meningoencephalitis model is $100 \%$ reproducible and does not require any additional methods of control.

On day 30-40 after the regression of the viral infection signs (weakness, hypokinesia, decreased food and water requirements), a hemorrhagic stroke was simulated in the survivors. Cerebral hemorrhage in animals was simulated by inoculation of $0.15-0.2 \mathrm{ml}$ of autologous blood into the right hemisphere $(\mathrm{L}=1.5 ; \mathrm{H}=3.0 ; \mathrm{AP}=1.0)$ [8]. For this purpose, we predefined coordinates of input of cannula with blood, with help of an stereotactic atlas [2]. All hematoma were localized in the right internal capsule of the brain.
Animals of group 3 were subsequently treated with $50 \mathrm{mg} / \mathrm{kg}$ of acyclovir intraperitoneally once a day for 10 days. After 10 days following drug administration, they were euthanized with observance of all bioethical norms and rules of the „Regulations on the animal use in biomedical research”, „European Convention for the protection of vertebrate animals used for experimental and other scientific purposes”, „Guide for the Care and Use of Laboratory Animals".

For histological examination, the murine brain was fixed in $10 \%$ formalin solution in $0.1 \mathrm{M}$ phosphate buffer (pH 7.4), and dehydrated in ascending concentrations of ethanol and embedded in paraffin as per the standard procedure. The 6-8 $\mu \mathrm{m}$ thick paraffin slices were stained with H\&En. The morphometric study included assessment of the changes in a number of damaged neurons in the frontal hippocampal sections. Herein, the microphotographs were taken with an Olympus BX 51 microscope. The morphometric analysis was performed using CarlZeiss (AxioVision SE64 Rel.4.9.1) software, magnification $\times 400$. Statistica 6.0 software was employed for statistical processing of the obtained data using Student t-test.

At the time of the euthanasia of the laboratory animals, hippocampal CA1 sector samples were isolated for electron microscopy. Fragments were fixed in $2.5 \%$ solution of glutaraldehyde in phosphate buffer, with postfixation in 1\% solution of osmium tetroxide. Dehydration was carried out in alcohols of ascending concentration $(70 \%, 80 \%, 90 \%$, $100 \%)$ and acetone. All biological samples were subsequently infiltrated and embedded in Araldite-Epon mixture. Ultrathin sections $(60-70 \mathrm{~nm})$ were contrasted with $2 \%$ solution of uranilacetate and lead citrate, studied and photographed under electron microscope (Tescan Mira 3 LMU (Czech Republic)) at magnification of 10-80 thousand.

PCR and dot-ELISA were used to confirm HSV-1 reproduction by detecting viral antigens in Vero cell culture. Vero cell culture was grown in sterile trays ("Nunc"). The infected trays were then incubated in culture medium ( $88 \%$ RPMI 1640 medium "Sigma") with the addition of $12 \%$ of heat inactivated fetal calf serum (FCS) and antibiotics at $37^{\circ} \mathrm{C}$ with $5 \%$ of $\mathrm{CO}_{2}$. Cytopathic activity (CPA) - syncytia formation - served as a marker of viral reproduction.

HSV-1 DNA in biological specimens was found by utilizing PCR with hybridization-fluorescent detection, using the set of reagents: "AmplySensR HSV-1, II-FL". A "DNAsorb-AM" set of reagents was used for DNA extraction. DNA was extracted from each studied specimen in the presence of an internal control specimen (BKO-FL).

Dot-ELISA was performed on nitrocellulose filters. The filters with the applied specimens were dried and immersed in the solution containing $30 \mathrm{mg} / \mathrm{ml} \mathrm{BSA}$ in $0.01 \mathrm{M}$ Tris $\mathrm{pH} 7.5-0.15 \mathrm{M} \mathrm{NaCl}$ buffer, and incubated for two hours at $37^{\circ} \mathrm{C}$. After the incubation in PAP (peroxidaseantiperoxidase complex), the filters were rinsed six times and immersed into the substrate for an enzyme to develop: $3.8 \mathrm{ml}$ of DAB (diaminobenzidine tetrachloride) $+0.2 \mathrm{ml}$ of $0.1 \% \mathrm{H}_{2} \mathrm{O}_{2}$. The reaction was registered when the centers of the wells turned yellow. 
To test the specificity of the response, we have set the following controls:

1. Control without protein A conjugate labeled with peroxidase.

2. Control of antigen without specific sera.

3. Control with normal rabbit serum.

4. The control sample without antigen.

\section{RESULTS AND DISCUSSION}

In our human test population, molecular biology techniques utilizing serum samples confirmed the presence of HSV-1. The dot-ELISA assay detected HSV-1 in $100 \%$ of samples, while the PCR gave negative results. Infectious herpes virus titer did not significantly differ in patients with three types of stroke: subarachnoid hemorrhage - 1,0-2,0 $\lg$ ID50, ischemic stroke - 1,0-1,5 $\mathrm{lg} \mathrm{ID}_{50}$, parenchymal nontraumatic hemorrhage - 1,5 lg ID50 (Tab. 2).

Table 2. HSV-1 in serum of patients with stroke (by ICD-10)

\begin{tabular}{|l|c|c|c|}
\hline \multicolumn{1}{|c|}{ Clinical case } & $\begin{array}{c}\text { CPA of the } \\
\text { infectious titer, } \\
\text { Ig ID } 50\end{array}$ & Dot-Elisa & PCR \\
\hline $\begin{array}{l}\text { Hemorrhagic } \\
\text { stroke (I.61) }\end{array}$ & 1.5 & positive & negative \\
\hline $\begin{array}{l}\text { Ischemic } \\
\text { stroke (I.63) }\end{array}$ & 1.5 & positive & negative \\
\hline $\begin{array}{l}\text { Ischemic } \\
\text { stroke (I.63) }\end{array}$ & 1.0 & positive & negative \\
\hline $\begin{array}{l}\text { Subarachnoid } \\
\text { hemorrhage (I.60) }\end{array}$ & 1.5 & positive & negative \\
\hline $\begin{array}{l}\text { Subarachnoid } \\
\text { hemorrhage (I.60) }\end{array}$ & 1.5 & positive & negative \\
\hline $\begin{array}{l}\text { Subarachnoid } \\
\text { hemorrhage (I.60) }\end{array}$ & 1.0 & positive & negative \\
\hline $\begin{array}{l}\text { Subarachnoid } \\
\text { hemorrhage (I.60) }\end{array}$ & 2.0 & & \\
\hline
\end{tabular}
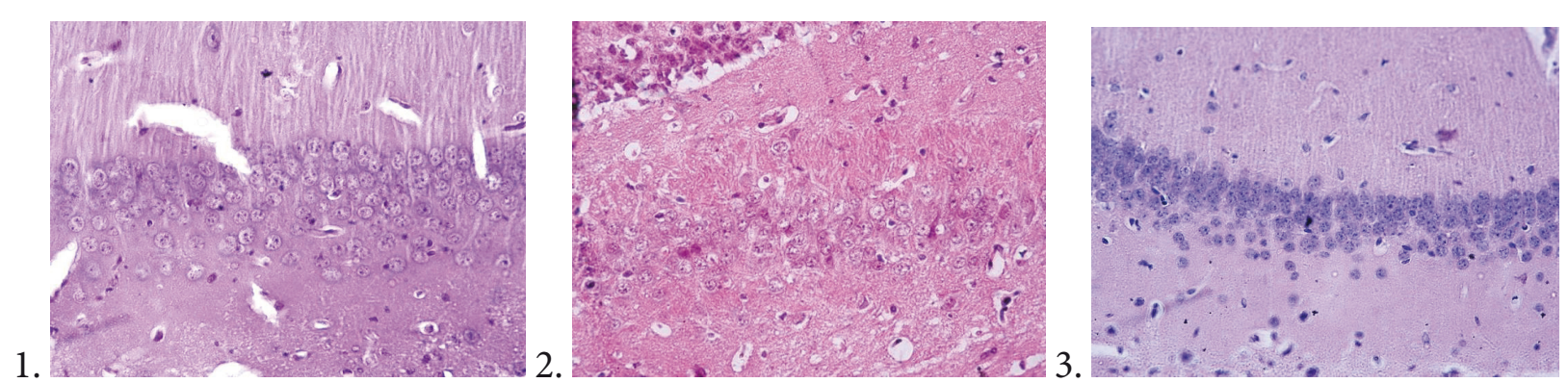

Figure 1. Histopathological changes. 1 - control group: intact pyramidal neurons (H\&E: $\times 400)$; 2 - group 2: neurodegeneration in CA1 hippocampal sector (H\&E: $\times 400) ; 3$ - more undamaged neurons, inhibition of neurodegeneration (H\&E: $\times 400)$.
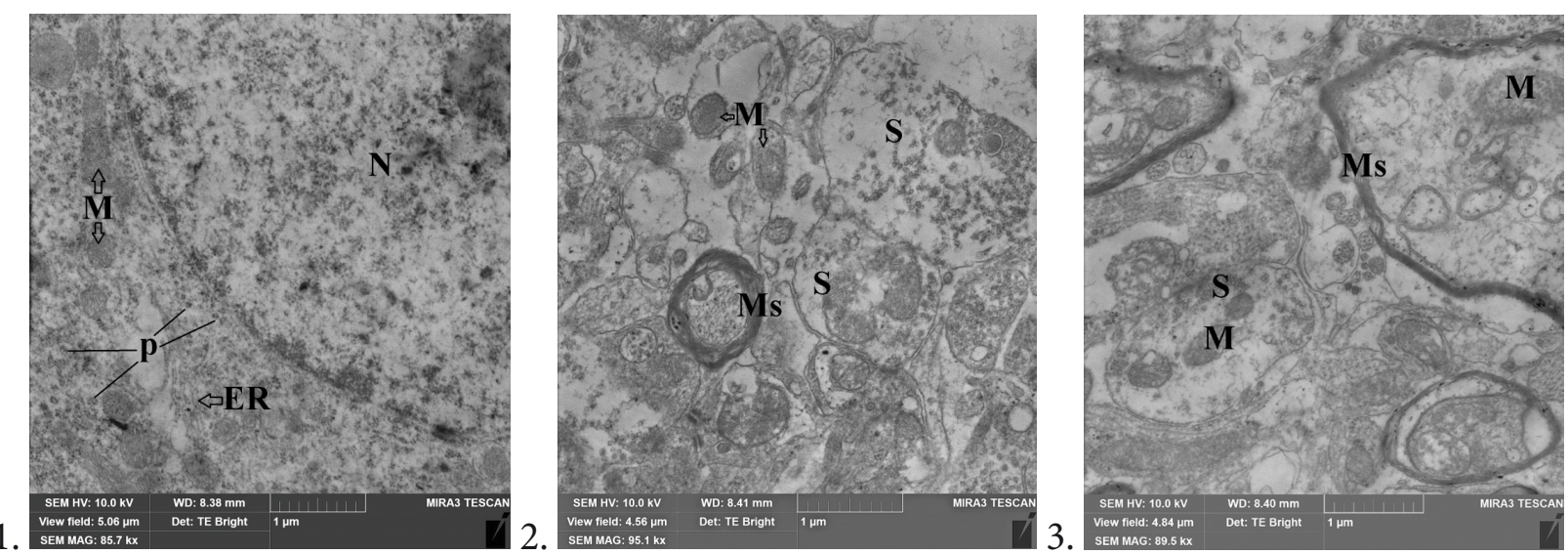

Figure 2. Electron microscopy changes in the hippocampus. 1 - Control group: intact nucleus, mitochondria and polysomes in neuron; 2 - group 2: destruction of synapses, nerve fibers and reduction of organelles in neurons; 3 - group 3: impairment of synapses, destruction of nerve fibers. ER - Endoplasmic reticulum, M - Mitochondria, Ms - Myelin sheath, N - Nucleus, p - Polysomes, S - Synapses 
compared with the group which did not receive the antiviral drug (Tab. 4). However, electron microscopy revealed impairment of neurons and gliocytes, disorganization and destruction of synapses, and the loss of cytoskeletal elements in the nerve fibers in both groups of animals (Fig. 2). In addition, we registered the emergence of lamellar membranous bodies in the cytoplasm of some neurons and gliocytes, but we did not observed any clusters and conglomerates of the newly formed virions. Therefore, the use of molecular biology techniques in the detection of HSV-1 in both the clinical and experimental material we consider to be have been appropriate and necessary.

Table 4. Morphometric parameters of hippocampal CA1 neurons sector

\begin{tabular}{|l|c|c|c|}
\hline \multirow{2}{*}{ Group } & \multicolumn{3}{|c|}{ Quantity of damaged neurons, \% } \\
\cline { 2 - 4 } & General quantity & $\begin{array}{c}\text { With hydropic } \\
\text { degeneration }\end{array}$ & With apoptosis \\
\hline Control & $5.6 \pm 0.1$ & $2.2 \pm 1.7$ & $3.0 \pm 0.4$ \\
\hline $\begin{array}{l}\text { HSV-1 with hemorrhagic } \\
\text { stroke }\end{array}$ & $62.0 \pm 4.2$ & $29.4 \pm 2.2$ & $32.5 \pm 4.3$ \\
\hline $\begin{array}{l}\text { HSV-1 with hemorrhagic } \\
\text { stroke+acyclovir }\end{array}$ & $28.7 \pm 0.7 *$ & $16.1 \pm 1.8 *$ & $12.5 \pm 1.4 *$ \\
\hline
\end{tabular}

* - statistically significant differences compared with group 2 - HSV-1 with hemorrhagic stroke $(p<0,05)$.

The research results allow us to conclude that hemorrhagic stroke is a pathogenic factor of HSV-1 reactivation. Still, the latter has yet to be completely studied in terms of diagnosis and therapy, and the results of laboratory detection of herpes infection in biological samples (blood, CSF) of healthy individuals and patients with stroke remain inadequately assessed. It is known, however, that about $90 \%$ of the population harbor type I herpes infection. Current literature contains a large body of clinical and experimental data regarding the detection of herpes infection; their amount is significantly lower in the works devoted to ischemic and traumatic brain injury. Zis et al. have described the case of ischemic stroke in the presence of herpetic encephalitis, and provide references for six similar cases [12]. In the work [5], a few cases of herpetic encephalitis in the presence of stroke were described, In both [5] and [12], however, the researchers note that there is a problem in testing for and identifying HSV, and they emphasized that accurate serologic diagnostics is needed because the MRI image of both pathologies is very similar. In fact, in regarding this pathology, there is significant variation of laboratory results published by different authors. Some studies have revealed theat the issue is with testing (detection of viruses), specifically, the choice of test kits containing antibodies to VZV and HSV, since ELISA assay may give conflicting data [3]. Therefore, the authors emphasize the need for more thorough diagnosis and verification of neuroinfection symptoms of herpes encephalitis and stroke. In our work, within the first 2 weeks, the PCR was negative, with sufficient quantities of $\operatorname{IgG}$ found [10]. The results of our clinical and laboratory study therefore has revealed the different sensitivities of assays at the early stages of viral infection in asymptomatic patients. Dot-Elisa was more sensitive and, hence, a more suitable assay than was PCR.

According to our data, herpes infection should be considered one of the therapeutic targets in the management of post-stroke complications. In our study, the use of acyclovir suppressed viral reproduction and the further development of infection. However, the primary lesion in the brain persisted. It seems that this antiviral drug only suppresses the reproduction of virions. Still, acyclovir can be used to prevent the development of HSV-1 infection in brain stroke. However, further search for drugs that are more effective is warranted. What is more, early diagnosis and treatment can begin with considering the results of serological tests for the detection of antigens to Herpes viridae. It should be noted that our results are important, not only for herpes virus infection, but may be useful for other viral, fungal and bacterial infections. A study of immunological response to viral neuroinfections in CNS lesions would be promising in engendering early diagnosis and treatment.

\section{CONCLUSIONS}

1. Hemorrhagic stroke is a pathogenic factor of HSV-I reactivation.

2. Dot-Elisa is a more sensitive and suitable assay for detecting the early stages of HSV-I infection, than is PCR.

3. The use of acyclovir in the experimental stroke suppressed HSV-I reproduction and further development of infection.

\section{REFERENCES}

1. Abbott A.L., Nicolaides A. N. Improving outcomes in patients with carotid stenosis. Call for better research opportunities and standards. Stroke, 46, 7, 2015.

2. Franklin K., Paxinos G. (2001). The mouse brain in stereotaxic coordinates. San Diego: Academic Press.

3. Grose C. Biological plausibility of a link between arterial ischemic stroke and infection with varicella-zoster virus or herpes simplex virus. Circulation, 133, 695, 2016.

4. Gumenyuk A.V. et al.: Mutual influence of herpes virus infection activate circulation impairment on the state of brain cells. Biopolymers and Cell, 32, 126, 2016.

5. Hara Y. et al.: Herpes simplex encephalitis initially presented with parietal cortex lesions mimicking acute ischemic stroke: A case report. Rinsho Shinkeigaku, 56, 104, 2016.

6. Joshi P.: Multiple strokes associated with herpes simplex virus type-2 infection: case report. J. Neurovirol., 22, 251, 2016.

7. Kalkonde Y.V., D et al.: Stroke is the leading cause of death in rural Gadchiroli, India. A prospective community-based study. Stroke, 46, 1764, 2015.

8. Savosko S.I. et al.: Features of Histostructural Changes in Rat Cerebral Cortex in Hemorrhagic Stroke Modeling. International Journal of Physiology and Pathophysiology, 4, 2, 113, 2013. http:// www.dl.begellhouse.comru/journals/6ec4ba27650016b1,3301bbf0 15c9d744,53bfe80d7lecddda.html

9. Snider, S.B. et al.: Hemorrhagic and ischemic stroke secondary to herpes simplex virus type 2 meningitis and vasculopathy. J Neurovirol., 20, 419, 2014.

10. Terlizzi V., et al.: Primary herpes virus infection and ischemic stroke in childhood: a new association? J. Clin. Neurosci., 21, 1656, 2014.

11. Zhang H., Li X.: Correlation between inflammatory factors and poststroke pneumonia in diabetic patients. Exp. Ther. Med., 1, 105, 2013.

12. Zis P., et al.: Herpes simplex virus type 2 encephalitis as a cause of ischemic stroke: case report and systematic review of the literature. J. Stroke Cerebrovasc Dis., 25, 335, 2016. 